Vitellinic acid

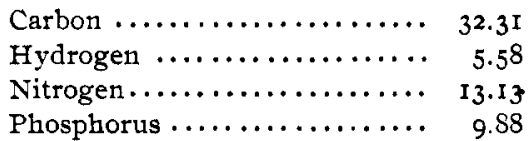

Ichtulinic acid.

32.56

6.00

14.00

10.34

Thus these "paranucleic" acids of different origin have a comparatively similar composition. The difference in the nitrogen is easily explained by the fact that the ichtulinic acid was obtained from the ammonium salt, and the vitellinic from the copper salt. If the latter acid is obtained from the ammonium salt it also contains about I 4 per cent. of nitrogen.

The nucleic acids analyzed were those of the pancreas of the cod-fish and fish sperm, and of the Bacillus tuberculosis.

Their composition was as follows :

\begin{tabular}{|c|c|c|c|}
\hline Carbon................. & $\begin{array}{c}\text { Pancreas. } \\
36.50\end{array}$ & $\begin{array}{c}\text { Cod-fish sperm. } \\
36.73\end{array}$ & $\begin{array}{c}\begin{array}{c}\text { Bacillus } \\
\text { tuberculosis. } \\
3^{8.7}\end{array}\end{array}$ \\
\hline Hydrogen........... & 4.69 & 5.12 & $6.3^{2}$ \\
\hline Nitrogen ............. & $16.7^{\circ}$ & 16.78 & 9.42 \\
\hline Phosphorus pentoxide.. & 20.16 & 20.47 & 29.40 \\
\hline
\end{tabular}

The acid obtained from the pancreas in distinction from the guanilic acid described by Bang contains in its molecule besides guanin also adenin. This acid as well as that of the cod-fish sperm does not differ much in its composition from the acids described within the last year by Schmideberg, Herlant, Osborne, and obtained from different sources.

The author also remarked that on precipitating the nucleic acids directly from tissues glycogen is precipitated simultaneously. The two can be separated by means of copper chloride. The nucleic acid forms a copper sait insoluble in water, while the copper compound of glycogen is soluble. By this method the author succeeded in obtaining glycogen from the pancreas, and a glycogen-like substance from the Bacillus tuberculosis.

\title{
ON THE ELIMINATION AND QUANTITATIVE ESTIMATION OF WATER IN OILS, FATS, AND WAXES.
}

\author{
BX CHARLES B. DAVIS.
}

Received March 19, rgor.

THE difficulty experienced while drying oils, fats, or waxes, (namely, loss by foaming and ejection, due to the contained water becoming overheated, as in the drying of the min- 
eral oil residue obtained after removal of the fatty oil by saponification, in the analysis of lubricants) can be very readily obviated by the following method:

Into a wide-mouthed glass-stoppered weighing-bottle (see fig-

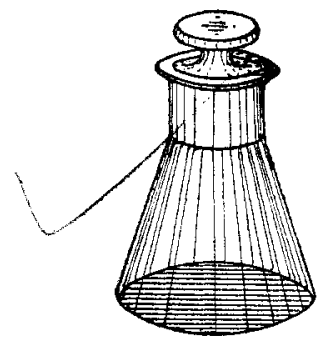
ure), is introduced sufficient thick filter-paper ${ }^{1}$ (in coil form) to half fill the vessel. The bottle and paper are now dried in the air-oven at $110^{\circ} \mathrm{C}$. to constant weight.

A portion of the sample is then added, in such quantity as will just saturate the filter-paper. The bottle being now closed and reweighed, the increase in weight gives the quantity of sample taken. The whole is now placed in the air-oven at $\mathrm{I} 10^{\circ} \mathrm{C} .,{ }^{2}$ and dried to constant weight. The decrease thus obtained, gives the water evaporated, which may be calculated to percentage from the data obtained above. Samples prone to oxidation are dried in an atmosphere of $\mathrm{CO}_{2}$ or $\mathrm{H}_{2}$.

In treating oils containing water, or where the whole of the residue is to be dried and the oil only determined, or the water simply eliminated, the sample is completely transferred to the tared bottle containing the dry filter-paper by means of ether, the ether removed by evaporation at slightly elevated temperature, after which it is dried in the air-oven as above described.

Solid fats and waxes are introduced into the weighing bottle prepared as above, in their natural state, which, upon being warmed to the temperature of the oven, are quickly absorbed by the filterpaper, and drying proceeded with as in the case of liquids."

By the above method, all foaming and ejection of the sample is eliminated, due to the fact that the oil, fat, or wax, and the water are thoroughly distributed throughout the paper while the drying operation is carried on.

A typical example of the value of the above method may be readily seen, and appreciated by referring to 'T. B. Stillman's "Engineering Chemistry," p. 368 , in which he condemns the drying of oils containing water on account of this loss by foaming and ejection.

\footnotetext{
1 Asbestos is not recommended on account of its property of retaining water even at $110^{\circ} \mathrm{C}$. (this Journal, 22,46 ).

2 Or at temperature other than $110^{\circ} \mathrm{C}$., in any case, the bottle, plus paper, is to be dried in the beginning at the same temperature.

If oil, fat, or wax be required for further examination, it may be removed from the paper by ether extraction in a Soxhlet apparatus.
} 